\title{
Somatosensory and motor evoked potential changes in patients with Pott's paraplegia
}

\author{
UK Misra and J Kalita \\ Department of Neurology, Sanjay Gandhi Postgraduate Institute of Medical Sciences, Lucknow 226 014, India
}

\begin{abstract}
The evoked potential changes in patients with Pott's paraplegia have not been reported in the literature. We conducted median and tibial somatosensory evoked potential (SEP) and central motor conduction studies to the upper and lower limbs in seven patients with this condition. The patients' age ranged from 20 to 71 years; four were males. The vertebral involvement was commonest in the lower thoracic region (4), and a cold abscess was present in five of the patients. Central motor conduction time (CMCT) to the lower limbs was unrecordable in 3 ( six sides) and prolonged in 3 patients (four sides). The tibial SEP was unrecordable in 4 patients (seven sides). Motor evoked potentials and SEP correlated with respective motor and sensory impairments, as well as with the outcome.
\end{abstract}

Keywords: Somatosensory and motor evoked potentials; tuberculosis of the spine; Pott's paraplegia

\section{Introduction}

Spinal tuberculosis is the commonest type of bone and joint tuberculosis, and is the most frequent cause of compression paraplegia in India. ${ }^{1}$ It is also likely to be important in other countries because of the resurgence of tuberculosis due to AIDS. The diagnosis and prognosis of Pott's paraplegia is often based on the clinical and radiological changes. Magnetic resonance imaging has proved to be a more sensitive technique compared to myelography and CT scan to demonstrate the nature and extent of lesions. ${ }^{2}$ The functional derangements can be objectively documented by sensory and motor evoked potentials. These techniques have been employed in the evaluation of a number of spinal cord diseases, such as spinal injuries, ${ }^{3}$ multiple sclerosis, ${ }^{4,5}$ acute transverse myelitis $^{6}$ and cervical myelopathy. ${ }^{7}$ In spite of the common occurrence of Pott's paraplegia, we could not find any report on this disease on evoked potential changes. In this communication, we report on motor and sensory evoked potential studies in Pott's paraplegia.

\section{Patients and methods}

Seven patients with paraplegia and clinical and radiological features of Pott's spine were included in this study. They were subjected to a detailed clinical examination including, power on a $0-5$ MRC (Medical Research Council) scale, reflexes, pinprick and joint position sense, bowel and bladder dysfunc-

Correspondence: UK Misra tion. Spasticity was graded by Ashworth scale which is a five point scale: grade $\mathrm{I}=$ no increase in tone, grade $\mathrm{II}=$ slight increase, grade $\mathrm{III}=$ moderate increase, grade $\mathrm{IV}=$ significant increase in tone making passive movements difficult and grade $\mathrm{V}=$ marked increase in tone making the joints immobile. ${ }^{8}$ Blood counts, ESR, blood sugar, serum chemistry, VDRL tests were carried out in all the patients. In the radiographs of spine, the presence of wedge collapse, reduction of intervertebral disc space and the presence of a cold abscess were noted. Myelogram and spinal MRI were carried out in three patients each. Ultrasound guided biopsy and aspiration were also undertaken in selected patients. The patients were given four drug antitubercular treatments comprising of Rifampicin, INH, Ethambutol and Pyrazinamide. The clinical and neurophysiological studies were repeated at the end of 1,3 and 6 months. The patients' disability was graded employing the Barthel Index (BI), which comprises the assessment of activities of daily life such as bowel, bladder, grooming, toilet use, feeding, walking, dressing, climbing stairs, bathing and bed to chair transfer. ${ }^{9}$ The maximum score was 20 . The outcome was defined on the basis of ADL score at the end of 3 months into complete $(\mathrm{BI}=20)$, partial $(\mathrm{BI}=19-12)$ and poor recovery $(\mathrm{BI}<12)$.

\section{Patient details}

Our observations are based on seven patients with Pott's paraplegia, their age ranged between 20 and 71 (mean 39.6) years and three of them were females. The diagnosis of Pott's paraplegia was based on the 
demonstration of acid fast bacilli in one and the characteristic histopathology in five patients. In the remaining two patients, the clinical and radiological pictures were consistent with the diagnosis of Pott's paraplegia. The duration of symptoms ranged between 3 and 36 months and all the patients had localised kyphosis or bone tenderness; one patient each had cervical (Patient No 2) and lumbar (Patient No 7) involvement. All the patients had varying degree of paraplegia except one, who had left upper limb weakness as well (Patient No 2). Three patients were bed ridden because of weakness; in the remaining the degree of weakness was milder (MRC grade III-IV). Urinary retention was present in four, and the sensory level ranged between L1 and T5; four patients had impaired joint position sense in legs and three did not have any sensory impairment. Radiographs of the spine revealed a reduced disc space with wedging of vertebra in all and cold abscess in five patients. One patient had involvement of pedicle of T9 vertebra on the right side (Patient No 4). Spinal MRI was carried out in three patients; in one patient both plain X-ray and myelogram carried out 1 month earlier were reported as normal. In all these patients MRI more clearly demonstrated the extent of cord compression. The clinical and radiological features are summarised in Table 1.

Evoked potential studies Motor and sensory pathways were evaluated by evoked potential studies.

Motor evoked potential (MEP) To stimulate the motor cortex, cervical and lumbar spine, a Digitimer D-180 stimulator delivering a single electrical shock up to $750 \mathrm{~V}$ with a time constant of $50-100 \mu$ s was used. The stimulating electrode was a $1 \mathrm{~cm}$ diameter saline soaked felt pad mounted on a plastic handle. To activate the abductor digiti minimi (ADM) the cathode was placed at the vertex, and anode $7 \mathrm{~cm}$ laterally and $1 \mathrm{~cm}$ anterior to a line drawn from vertex to tragus. For activating of the tibialis anterior (TA) the anode was kept at the vertex and cathode $7 \mathrm{~cm}$ posterior to it. For cervical and lumbar stimulation the cathode was placed below the spinous process of seventh cervical
(C7) and twelfth thoracic vertebra (T12) respectively, with the anode proximal to the cathode. Motor evoked potentials were recorded by surface electrode placed on ADM or TA in a belly tendon montage. During the cortical stimulation the patients were asked to contract the target muscle slightly ( $10 \%$ of maximum force) whereas during spinal stimulation they were asked to relax. The EMG signals were filtered through $20 \mathrm{~Hz}-$ $2 \mathrm{KHz}$, at a gain of $0.5-2 \mathrm{mV} /$ division. Stimulus intensity was $90-100 \%$ for cortical and $50-60 \%$ of maximum output for spinal stimulation. Onset latency and amplitude of the negative phase of MEP was recorded. Central motor conduction time (CMCT) was calculated for the upper limb (CMCT-ADM) by subtracting the latency on $\mathrm{C} 7$ stimulation from that on cortical stimulation, and that for the lower limb (CMCT-TA) by subtracting the latency on L1 stimulation from that on vertex. ${ }^{10}$

Table 2 Evoked potential changes in Pott's paraplegia

\begin{tabular}{|c|c|c|c|}
\hline $\mathrm{No}$ & Day & $\begin{array}{c}C M C T-T A \\
(m s) \\
R t / L t\end{array}$ & $\begin{array}{c}\text { Tibial SEP } \\
\text { (N19-P40) } \\
(m s) \\
\text { Rt/Lt }\end{array}$ \\
\hline \multirow[t]{4}{*}{1} & 1 & NR/NR & NR/NR \\
\hline & 90 & $24.0 / 24.8$ & NR/NR \\
\hline & 180 & $20.8 / 16.4$ & $41.0 / 25.0$ \\
\hline & 300 & $10.0 / 12.0$ & $24.0 / 21.0$ \\
\hline \multirow[t]{2}{*}{$2^{*}$} & 1 & $10.8 / 10.6$ & $19.2 / 18.6$ \\
\hline & 90 & $9.2 / 10.0$ & $19.2 / 18.6$ \\
\hline \multirow[t]{2}{*}{3} & 1 & $10.0 / 27.2$ & $26.0 / 25.0$ \\
\hline & 90 & $10.0 / 13.6$ & $22.4 / 21.6$ \\
\hline \multirow[t]{3}{*}{4} & 1 & NR/NR & $23.0 / \mathrm{NR}$ \\
\hline & 30 & $30.8 / 25.6$ & $21.0 / 31.0$ \\
\hline & 90 & $26.4 / 26.8$ & $21.0 / 20.0$ \\
\hline 5 & 1 & $25.6 / 24.4$ & NR/NR \\
\hline 6 & 1 & NR/NR & NR/NR \\
\hline \multirow[t]{2}{*}{7} & 1 & $14.8 / 20.4$ & $25.0 / 25.0$ \\
\hline & 90 & $14.0 / 13.6$ & $24.0 / 26.0$ \\
\hline $\begin{array}{l}\text { Upper limit } \\
\text { of normal }\end{array}$ & & 16.1 & 27.1 \\
\hline
\end{tabular}

${ }^{*}$ Lt CMCT-ADM was 8.6 (Normal upper limit $8.1 \mathrm{~ms}$ ). $\mathrm{CMCT}=$ Central motor conduction time, SEP = Somatosensory evoked potential, NR $=$ Not recordable

Table 1 Presenting clinical features of the patients with Pott's paraplegia

\begin{tabular}{|c|c|c|c|c|c|c|c|c|c|c|}
\hline \multirow[b]{2}{*}{ No } & \multirow[b]{2}{*}{ Age/Sex } & \multirow{2}{*}{$\begin{array}{c}\text { Duration } \\
\text { (month) }\end{array}$} & \multirow[b]{2}{*}{ Power } & \multicolumn{2}{|c|}{ Sensation } & \multirow{2}{*}{$\begin{array}{c}\text { Bladder } \\
\text { involvement }\end{array}$} & \multirow[b]{2}{*}{ Collapse } & \multirow[b]{2}{*}{ Abscess } & \multirow[b]{2}{*}{ Outcome } & \multirow[b]{2}{*}{ (3 month BI) } \\
\hline & & & & $P p$ & $J P s$ & & & & & \\
\hline 1 & $23 / \mathrm{M}$ & 5 & 2 & D5 & LL & + & D1 & + & $\mathrm{P}$ & (18) \\
\hline 2 & $20 / \mathrm{F}$ & 10 & 4 & $\mathrm{~N}$ & $\mathbf{N}$ & - & $\mathrm{C} 7-\mathrm{T} 1$ & + & $\mathrm{P}$ & (15) \\
\hline 3 & $30 / \mathrm{F}$ & 6 & 3 & $\mathrm{~N}$ & $\mathrm{~N}$ & - & D10 & + & $\mathrm{C}$ & (20) \\
\hline 4 & $20 / \mathrm{M}$ & 3 & 0 & D9 & LL & + & D9* & + & $\mathrm{C}$ & (20) \\
\hline 5 & $55 / \mathrm{F}$ & 12 & 3 & L1 & LL & + & D11 & - & - & - \\
\hline 6 & $71 / \mathrm{M}$ & 3 & 0 & D9 & LL & + & D9 & - & - & - \\
\hline 7 & $55 / \mathrm{M}$ & 36 & 4 & $\mathrm{~N}$ & $\mathrm{~N}$ & - & L3-4 & + & $\mathrm{C}$ & (20) \\
\hline
\end{tabular}

*Pedicle involvement, $\mathrm{N}=$ Normal, $\mathrm{LL}=$ Lower $\mathrm{Limb}, \mathrm{Pp}=$ Pin prick, JPs $=$ Joint position sense, $\mathrm{P}=\mathrm{Partial}, \mathrm{C}=\mathrm{Complete}$, $\mathrm{BI}=$ Barthel Index 
Somatosensory evoked potentials (SEP) Median and tibial SEPs were recorded by stimulating the median nerve at the wrist and the tibial nerve at the ankle by $0.1 \mathrm{~ms}$ square wave pulse at $3 \mathrm{~Hz}$ sufficient to produce a painless twitch. The recordings were obtained from the contralateral parietal cortex and ipsilateral Erb's point referred to $\mathrm{Fz}$ for median SEP and $\mathrm{Cz}(2 \mathrm{~cm}$ posterior to $\mathrm{Cz}$ ) referred to $\mathrm{Fz}$ and $\mathrm{L} 1$ referred to $\mathrm{L} 3$ for tibial SEP. Five hundred and twelve responses were twice averaged at a gain of $2 \mu \mathrm{v} /$ division, sweep time $100 \mathrm{~ms}$, filter setting $2-3000 \mathrm{~Hz}$. N9-N20 conduction time for median SEP was calculated by the difference between the latencies of N20 and Erb's point; and N19-P40 conduction time for tibial SEP was calculated as the difference between the latencies of cortical potential P40 and lumbar potential N19. ${ }^{6}$ The evoked potential results were compared with our laboratory's normal values, which were obtained from 32 healthy volunteers whose age ranged between 15 and 60 years. The upper limit of normal was defined as mean \pm 2.5 SD of controls. The upper limit of CMCT$\mathrm{ADM}($ Mean $\pm \mathrm{SD})$ was $8.1(5.1 \pm 1.2) \mathrm{ms}$; CMCT-TA $16.1(12.1 \pm 1.6) \mathrm{ms}$; median $\mathrm{N} 9-\mathrm{N} 20$ conduction time $11.3(8.3 \pm 1.2) \mathrm{ms}$ and tibial N19-N40 conduction time was $27.1(20.1 \pm 2.8) \mathrm{ms}$. The relationship of motor and sensory impairment with respective evoked potentials were evaluated by employing the $\chi^{2}$ test.

\section{Results}

Evoked potential studies were carried out in seven patients with Pott's paraplegia and five of whom were followed up.

Central motor conduction to the upper limbs was normal in all except one patient (Patient No 2) in whom it correlated with left upper limb weakness. CMCT-TA was abnormal in all except one patient (Patient No 2). It was unrecordable in three (six sides) and prolonged in three patients (four sides). MEP correlated with leg weakness $\left(\chi^{2}=24, \mathrm{df}=2, \mathrm{P}<0.01\right)$. Tibial somatosensory evoked potentials were less frequently abnormal; being unrecordable in 4 patients (7 sides). Median SEPs however were normal in all the patients. The SEP abnormalities also correlated with joint position sensation in the lower limbs $\left(\chi^{2}=9.1\right.$, $\mathrm{df}=1, P<0.01)$. The evoked potential data are given in Table 2.

Serial studies were possible in five patients and revealed improvement in both MEPs and SEPs. The initial unrecordable MEP became recordable in two patients (four sides) at 3 months. Both of these had prolonged CMCT-TA. However, it was found to be normal in one patient at 10 months follow-up. Prolonged CMCT improved to normal in two patients (two sides). Similarly both the patients with unrecordable tibial SEP had normal CSCT (N19-P40) at 3 and 10 months follow-up respectively. Both MEP and SEP improvement correlated with respective motor and sensory deficits.

Clinical correlation The results of follow-up are presented in Table 3. Out of five patients followed up; two had pronounced weakness of lower limbs (grade 0 and grade 2). Initial MEP was unrecordable in both these patients. The clinical improvement in power correlated with improvement of CMCT. The time needed for CMCT to normalise was variable; it took 3 months in one and 10 months in another patient. The remaining three patients had milder weakness (grade IV); two of whom had prolonged CMCT-TA. All the patients with mild weakness improved with normal power by 3 months and CMCT in them was also normal. Muscle tone returned to normal in four out of five patients. Hyperreflexia of knee and ankle however persisted in all.

Two patients with abnormal joint position and pin

Table 3 Serial changes in motor and sensory impairment (lower limb) in patients with spinal tuberculosis

\begin{tabular}{|c|c|c|c|c|c|c|c|c|c|c|c|}
\hline \multirow[b]{2}{*}{ No } & \multirow[b]{2}{*}{ Day } & \multicolumn{2}{|c|}{ Power } & \multicolumn{2}{|c|}{ Tone } & \multicolumn{2}{|c|}{ Reflex } & \multicolumn{2}{|c|}{ Pinprick } & \multicolumn{2}{|c|}{$J P S$} \\
\hline & & $R$ & $L$ & $R$ & $L$ & $R$ & $L$ & $R$ & $L$ & $R$ & $L$ \\
\hline \multirow[t]{4}{*}{1} & 1 & 2 & 2 & 2 & 2 & $\uparrow$ & $\uparrow$ & Red & Red & Red & Red \\
\hline & 90 & 4 & 4 & 2 & 2 & $\uparrow$ & $\uparrow$ & Red & Red & Red & Red \\
\hline & 180 & 4 & 4 & 2 & 2 & $\uparrow$ & $\uparrow$ & $\mathrm{N}$ & $\mathrm{N}$ & Red & Red \\
\hline & 300 & 5 & 5 & 1 & 1 & $\uparrow$ & $\uparrow$ & $\mathrm{N}$ & $\mathrm{N}$ & $\mathrm{N}$ & $\mathrm{N}$ \\
\hline \multirow[t]{2}{*}{2} & 1 & $4^{*}$ & $4^{*}$ & 1 & 1 & $\uparrow$ & $\uparrow$ & Red & Red & $\mathbf{N}$ & $\mathbf{N}$ \\
\hline & 90 & 5 & 5 & 1 & 1 & $\uparrow$ & $\uparrow$ & $\mathbf{N}$ & $\mathbf{N}$ & $\mathbf{N}$ & $\mathbf{N}$ \\
\hline \multirow[t]{2}{*}{3} & 1 & 4 & 4 & 2 & 2 & $\uparrow$ & $\uparrow$ & $\mathbf{N}$ & $\mathrm{N}$ & $\mathbf{N}$ & $\mathbf{N}$ \\
\hline & 90 & 5 & 5 & 1 & 1 & $\uparrow$ & $\uparrow$ & $\mathrm{N}$ & $\mathrm{N}$ & $\mathbf{N}$ & $\mathbf{N}$ \\
\hline \multirow[t]{3}{*}{4} & 1 & 0 & 0 & 2 & 2 & $\uparrow$ & $\uparrow$ & A & A & A & A \\
\hline & 30 & 4 & 4 & 2 & 2 & $\uparrow$ & $\uparrow$ & Red & Red & Red & Red \\
\hline & 90 & 4 & 4 & 2 & 2 & $\uparrow$ & $\uparrow$ & Red & Red & Red & Red \\
\hline \multirow[t]{2}{*}{7} & 1 & 4 & 4 & 1 & 1 & $\uparrow$ & $\uparrow$ & $\mathrm{N}$ & $\mathrm{N}$ & $\mathbf{N}$ & $\mathrm{N}$ \\
\hline & 90 & 5 & 5 & 1 & 1 & $\uparrow$ & $\uparrow$ & $\mathrm{N}$ & $\mathrm{N}$ & $\mathbf{N}$ & $\mathbf{N}$ \\
\hline
\end{tabular}

*Upper limb involvement; $\uparrow=$ increased; $A=$ absent; $\mathrm{N}=$ normal; Red= reduced; JPS = joint position sense; $\mathrm{R}=$ right; $\mathrm{L}=$ left. Power graded in MRC scale and tone in Ashworth scale 
prick sensations had unrecordable tibial SEPs. Tibial SEPs returned to normal in both these patients. This was associated with recovery of joint position sense at 10 months in one patient; whereas in the other SEP became normal in spite of persistent sensory impairment. Comparing the frequency of abnormality and improvement pattern of motor and sensory evoked potentials; MEP was more frequently abnormal and was earlier to recover than SEP.

By the end of 3 months, three patients had complete and two had partial recovery. The latter patients were clinically followed up after 1 year and both recovered completely. Both MEP and SEP correlated with respective motor and sensory improvement. Initial MEP and SEP however did not correlate with three month outcome, because unrecordable MEP was associated with partial and complete recovery in one patient each. Similarly in the patients with recordable MEP, one had partial and two had complete recovery.

\section{Discussion}

We found a wide spectrum of MEP and SEP changes comprising unrecordable, delayed and even normal results in patients with Pott's paraplegia. The evoked potential abnormalities were pronounced in the lower limbs and CMCT to upper limbs was abnormal in one

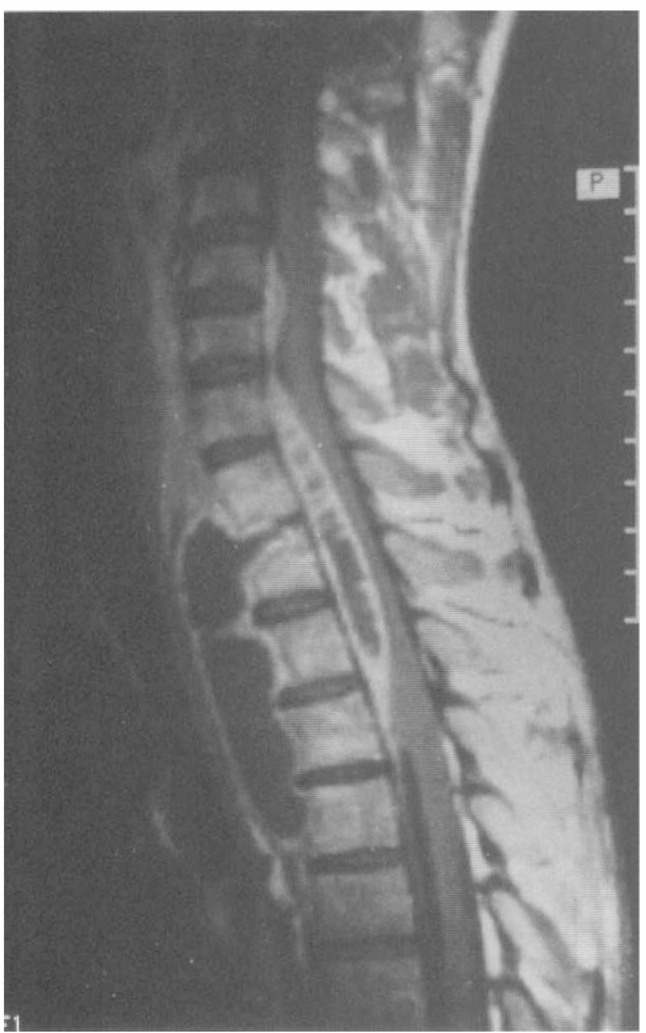

Figure 1 Gadolinium enhanced spinal MRI in sagittal section showing prevertebral abscess with epidural communication producing cord compression (Patient No 1) patient only. Prominent lower limb MEP abnormalities are consistent with prediliction of tuberculous pathology to mid thoracic region. In Pott's paraplegia, the mid thoracic region is involved in $47 \%$, lower dorsal and upper lumbar in $35 \%$, cervicodorsal in $16 \%$; and $60 \%$ of the latter group develop paraplegia. ${ }^{1}$ In our study, however, the lower thoracic region was most frequently involved. The higher frequency of MEP

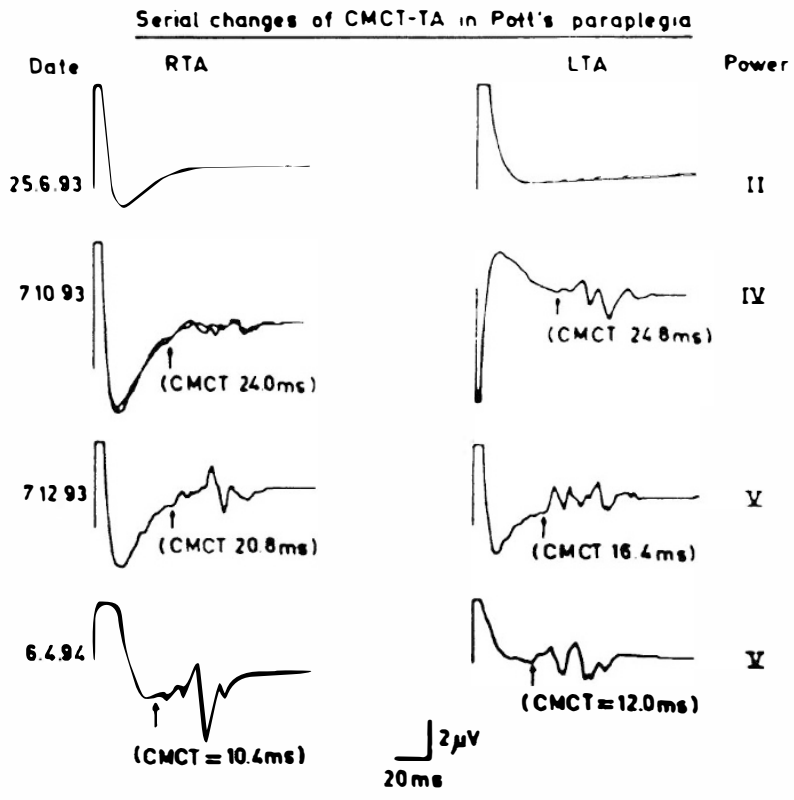

Figure 2 Sequential changes in the central motor conduction in a patient with Pott's paraplegia (Patient No 1). Initially unrecordable MEP became recordable at 3 months but CMCT remained prolonged till 6 months which returned to normal at 10 months followup. This was associated with improvement in lower limb power from grade II to IV at 3 months. At 10 months followup the only abnormality was knee and ankle hyperreflexia

Serial Study of Tibial SEP in Pott's paraplegia
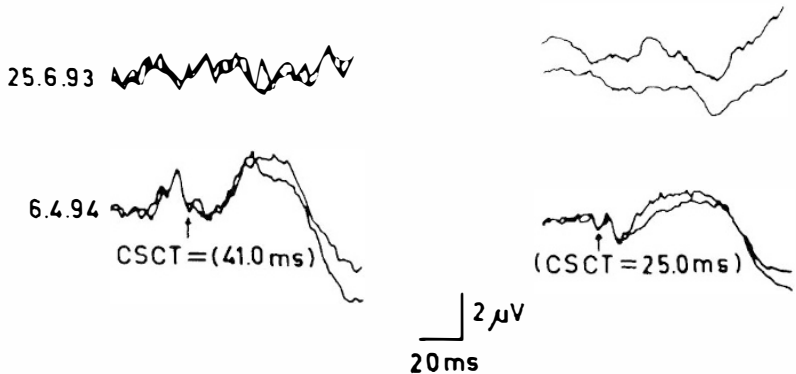

Figure 3 Shows tibial SEP changes in a patients with Pott's paraplegia who had impaired joint position and pinprick sensations (Patient No 1); SEP remained unrecordable till 3 months. At 6 months pinprick sensations were normal but joint position sensations were impaired, which was associated with prolonged CSCT on right side 
abnormalities compared to SEP may be attributed to the characteristic location of tubercular pathology in the vertebral body. Initially the anterior part of the body is involved resulting in wedge collapse. The anterior location of tubercular infection is responsible for the compression of anteriorly located corticospinal fibres hence the MEP abnormalities. Cord compression in paraplegia is attributed to paravertebral abscess entering the spinal canal, granulation tissue encircling the dura, sequestrated bone and intervertebral disc, dislocated vertebra and fibrotic bar. ${ }^{1}$ In our patients, wedge collapse was found in all and there was cold abscess in five. The involvement of pedicles, although reported is uncommon in tuberculosis. One of our patients with characteristic histopathology of tuberculosis had erosion of the right pedicle of 9th thoracic vertebra. The tibial SEP is less frequently abnormal, compared to MEPs in Pott's paraplegia, but the abnormality is consistent with advanced cord compression. Out of four patients with unrecordable SEP, two had cold abscess communicating with the spinal canal and severe cord compression due to wedge collapse and posterior arch tuberculosis was present in one patient each.

The fast conducting motor pathways were evaluated by transcranial stimulation. Severe damage or compression to the motor fibres may result in inexcitability of the motor pathways. In our study three patients had unrecordable MEP on cortical stimulation. Normal peripheral responses, however, excluded the possibilities of associated radiculopathy or anterior horn cell damage. Prolongation of CMCT in three of our patients (four limbs) may be due to demyelination of corticospinal fibres, conduction along oligosynaptic pathways and reduction in the size and synchrony of the descending volleys reaching the anterior horn cell. ${ }^{11}$ The pattern of MEP abnormalities in cervical compression myelopathies indicates that lower limb MEPs are more frequently abnormal in extramedullary and upper limb in intramedullary cord compression because of lamination of pyramidal fibres. ${ }^{7}$ Unilateral upper limb CMCT abnormality with normal peripheral conduction and normal MRI rendered the possibilities of radiculopathy and intraspinal granuloma less likely. A small granuloma or an ischemic spinal cord lesion, however, can be missed in spinal MRI.

Unrecordable MEPs and SEPs have been reported to predict a poor outcome in spinal cord injuries and acute transverse myelitis. ${ }^{6}$ In Pott's paraplegia MEP and SEP abnormalities have revealed progressive improvement. This may be attributed to the natural history of the disease and its response to treatment. Our results therefore, are in striking contrast to those found in traumatic and ischemic myelopathy ${ }^{3}$ (Kalita and Misra unpublished observations).

From this study we conclude that evoked potential studies are helpful in objectively documenting the respective sensory and motor deficits. In Pott's paraplegia, MEP is more frequently abnormal compared to SEP and correlates with respective clinical improvement.

\section{Acknowledgements}

We thank SP Singh for technical assistance, VK Tripathi for typing the script and Anil Kumar for preparing the illustrations.

\section{References}

1 Tandon PN, Pathak SN. Tuberculosis of central nervous system. In: Tropical Neurology. (ed.) Spillane JD. Oxford University Press, London, 1973; pp. 37-62.

2 Modic MT et al. Vertebral osteomyelitis: Assessment using MR. Radiology, 1985; 157, 157-166.

3 Yannikas C. Short latency somatosensory evoked potentials in Nerve lesion, plexopathies, radiculopathies and spinal cord trauma. In: Evoked potentials in clinical medicine. (ed.) Chiappa KH. 2nd ed, Raven Press: New York, 1989; pp. 439-468.

4 Chiappa KH. Pattern shift visual brainstem auditory and short latency somatosensory evoked potentials in multiple sclerosis. Neurology, 1980; 30, 110-129.

5 Hess CW, Mills KR, Murray NMF, Schriefer TN. Magnetic brain stimulation: Central motor conduction. Ann. Neurol., 1987, 22, 744-752.

6 Misra UK, Kalita J. Transverse myelitis, Neurophysiological and MRI correlations. Paraplegia, 1994; 32, 593-596.

7 Brunholzl C, Claus D. Central motor conduction time to upper and lower limbs in cervical cord lesions. Arch. Neurol., 1994; 51, $245-249$.

8 Penn RD et al. Intrathecal baclofen for severe spinal spasticity. N. Engl. J. Med. 1989; 320, 1517-1521.

9 Mahony FI, Barthel DW. Functional evaluation: the Barthel index. Md. State Med. J., 1965 14, 61-65.

10 Misra UK, Sharma VP. Central and peripheral conduction studies in neurolathyrism. J. Neurol. Neurosurg. Psychiat., 1994; 57, $572-577$.

11 Felix D, Wiesendanger M. Pyramidal and nonpyramidal motor cortical effects on distal forelimb muscles of monkeys. Experimental Brain Research, 1971; 12, 81-91. 